\title{
Reproductive decision-making in the context of mitochondrial DNA disorders: views and experiences of professionals
}

Citation for published version (APA):

Bredenoord, A. L., Krumeich, A., De Vries, M. C., Dondorp, W., \& De Wert, G. (2010). Reproductive decision-making in the context of mitochondrial DNA disorders: views and experiences of professionals. Clinical Genetics, 77(1), 10-17. https://doi.org/10.1111/j.1399-0004.2009.01312.x

Document status and date:

Published: 01/01/2010

DOI:

10.1111/j.1399-0004.2009.01312.x

Document Version:

Publisher's PDF, also known as Version of record

Document license:

Taverne

Please check the document version of this publication:

- A submitted manuscript is the version of the article upon submission and before peer-review. There can be important differences between the submitted version and the official published version of record.

People interested in the research are advised to contact the author for the final version of the publication, or visit the DOI to the publisher's website.

- The final author version and the galley proof are versions of the publication after peer review.

- The final published version features the final layout of the paper including the volume, issue and page numbers.

Link to publication

\footnotetext{
General rights rights.

- You may freely distribute the URL identifying the publication in the public portal. please follow below link for the End User Agreement:

www.umlib.nl/taverne-license

Take down policy

If you believe that this document breaches copyright please contact us at:

repository@maastrichtuniversity.nl

providing details and we will investigate your claim.
}

Copyright and moral rights for the publications made accessible in the public portal are retained by the authors and/or other copyright owners and it is a condition of accessing publications that users recognise and abide by the legal requirements associated with these

- Users may download and print one copy of any publication from the public portal for the purpose of private study or research.

- You may not further distribute the material or use it for any profit-making activity or commercial gain

If the publication is distributed under the terms of Article $25 \mathrm{fa}$ of the Dutch Copyright Act, indicated by the "Taverne" license above, 


\title{
Social and Behavioural Research in Clinical Genetics
}

\author{
Section Editor: \\ Barbara Bowles Biesecker, email: barbarab@mail.nih.gov
}

\section{Reproductive decision-making in the context of mitochondrial DNA disorders: views and experiences of professionals}

Bredenoord AL, Krumeich A, De Vries MC, Dondorp W, De Wert G. Reproductive decision-making in the context of mitochondrial DNA disorders: views and experiences of professionals. Clin Genet 2010: 77: 10-17. (C) John Wiley \& Sons A/S, 2010

Although a scientific and ethical debate about the possible reproductive options for carriers of mitochondrial DNA (mtDNA) mutations is developing, not much information regarding the views and experiences of professionals exists. This paper explores the attitudes and experiences of professionals involved on a daily basis with their patients' reproductive decision-making in the context of mtDNA disease. Qualitative international multicenter design using in-depth semi-structured interviews with 20 professionals has been utilized. We identified four main themes emerging from the interviews. Firstly, we illustrate the discussion among professionals as to what extent mitochondrial genetics differs from other areas in genetics, both technically and ethically. Secondly, we show the discomfort and doubts of professionals when an mtDNA mutation is involved, because of the uncertainty remaining after testing. Thirdly, we discuss how professionals struggle with the tension between, on the one hand, the ideal of reproductive autonomy and, on the other hand, the reality of their professional responsibility and complex clinical decision-making. Fourthly, we delineate the strategies used by professionals in order to make attempts to control uncertainty. This paper illustrates the impact on professionals of reproductive decision-making in the context of mtDNA disease. It shows their feelings of discomfort when interpreting and explaining uncertain or ambiguous data and may be perceived as an example of how professionals deal with the inherent limitations in genetic knowledge representing the state of the art. Insight into the experiences of professionals may contribute to a further improvement of reproductive genetic counseling in the context of mtDNA disorders.

\section{AL Bredenoord ${ }^{a}$, A Krumeich $^{a}$, MC De Vries ${ }^{b}$, W Dondorp ${ }^{a}$ and G De Wert ${ }^{\mathrm{a}}$}

aMaastricht University, Faculty of Health, Medicine and Life Sciences, Health, Ethics \& Society, Research Institutes GROW and CAPHRI Maastricht, the Netherlands, and bepartment of Paediatrics/Department of Medical Ethics and Law, Leiden University Medical Center, Leiden, the Netherlands

\begin{abstract}
Key words: ethics - interviews mitochondrial DNA disorders preimplantation genetic diagnosis prenatal diagnosis - professionals'

views - reproductive decision-making

Corresponding author: Annelien Bredenoord, Maastricht University, Faculty of Health, Medicine and Life Sciences, Health, Ethics \& Society/Research Institute GROW, PO Box 616, 6200 MD Maastricht, the Netherlands.

Tel.: +31 64107 4365;

fax: +31 88755 5485;

e-mail: A.L.Bredenoord@umcutrecht.nl
\end{abstract}

Received 15 June 2009, revised and accepted for publication 25 August 2009
With the proliferation of reproductive genetic technology, the options for couples at risk of transmitting a genetic mutation increase. The more technology, the more choice, the more demands are made on the competence of the professional to guide couples in their decision-making process (1).
In this paper we examine the attitudes and experiences of professionals with their role in reproductive decision-making in the context of mitochondrial DNA (mtDNA) disorders. Women at risk of transmitting an mtDNA mutation increasingly ask for options to avoid the birth of an (other) 


\section{Reproductive decision-making in mitochondrial DNA disorders}

affected child. However, due to the specific characteristics of mtDNA inheritance, making reliable predictions about the health of future offspring is difficult. Whereas a certain margin of uncertainty always has to be reckoned with when applying prenatal diagnosis (PND) and preimplantation genetic diagnosis (PGD), this counts a fortiori in the context of mtDNA disorders (2). Although morally acceptable under specific conditions, PND and PGD for mtDNA disorders may only reduce reproductive risk and residual uncertainties cannot be ruled out (3) [see text box 1]. aims to illustrate how professionals deal with the uncertainties and ethical peculiarities that are (currently) linked to reproductive decision-making in the context of mtDNA disease.

\section{Materials and methods}

The views, experiences and attitudes of professionals were examined by means of a qualitative interview design (12). One-to-one, in-depth, semistructured interviews $(n=20)$ were conducted with professionals from different background and

\section{Text box 1: background}

MtDNA disorders are a group of disorders relating to the mitochondria, which are the 'powerhouses' of the cell. Defects of mitochondrial function are increasingly recognized as important causes of disease. The clinical phenotype of mtDNA diseases is extremely variable, affecting patients at any age and in a wide variety of tissues. As there is currently no adequate treatment, the focus is on preventing the transmission of an mtDNA mutation from mother to child. Current reproductive options that maintain the genetic link to both prospective parents regard PND and PGD. Since the 1990s, PND for mtDNA mutations is increasingly offered [see for an overview (2)]. PGD for mtDNA mutations has only been reported twice, once for homoplasmic Leber hereditary optic neuropathy (LHON), which did not result in a pregnancy (4) and once for the heteroplasmic m.8993T $>G$ NARP mutation, resulting in a thus far healthy child (5). Although there is little experience with PGD for mtDNA disorder, it is increasingly considered to be an option for carriers of mtDNA mutations.

Mitochondrial disorders can be caused by a mutation in the nuclear DNA, by a mutation in the mtDNA and by an unknown genetic defect. Diseases due to mtDNA defects show some specific characteristics, which make it very challenging to estimate recurrence risks correctly and to predict whether a future child will be clinically affected. Firstly, many mutations are heteroplasmic. This means that there is a mixture of normal and mutant mtDNA, the level of which can differ among tissues. If the mutant load, i.e. the ratio of mutant to normal mtDNA, exceeds a specific threshold, clinical features become manifest. However, the exact threshold to disease expression is often not known. This makes it complex to predict on grounds of a (prenatal/preimplantation) test result whether the child is likely to develop disease symptoms. Secondly, the mtDNA is maternally inherited. Extreme shifts in mutant load can be observed between mother and child and also siblings can have variable levels of mutant load.

In other words, reproductive decision making in the context of mtDNA disorders is a complex enterprise. It is difficult to estimate the recurrence risk for a couple and if one decides to conduct PND or PGD, it is due to heteroplasmy often very difficult to interpret the test results and to predict the phenotype of the child. This raises ethical issues about the acceptability of residual uncertainties $(2,5-11)$.

Whereas a scientific and scholarly ethical debate about the possible reproductive options for carriers of mtDNA mutations is developing, not much information regarding the experiences of professionals working in mitochondrial genetics exists. What are their concerns, worries and points of view? What do they consider to be the major ethical issues? The purpose of our study was to explore the attitudes and experiences of professionals involved on a daily basis with treating patients with mitochondrial disease and counseling couples with a wish for a child. This paper specialties (Table 1). It concerned both basic scientists working at the bench and clinicians treating patients and counseling couples with a wish for a child. By selecting respondents of different nationalities and of different profession and background, with diverse views and perspectives, we aimed to collect a range of opinions and experiences as wide as possible (13).

We selected respondents from four European countries: Italy, France, the United Kingdom and the Netherlands. These countries were co-participants in a EU-funded project on 
Table 1. Background of interviewed professionals

\begin{tabular}{|c|c|c|c|}
\hline Number & Department & Profession & Sex \\
\hline P1 & Neurology & Neurologist & M \\
\hline P2 & Pediatrics & Pediatrician & M \\
\hline P3 & Neurology & Neurologist & M \\
\hline P4 & Neurology & Researcher & M \\
\hline P5 & Reproductive medicine & Gynecologist & M \\
\hline P6 & Clinical genetics & Clinical geneticist & M \\
\hline P7 & Pediatrics & Pediatric neurologist & $\mathrm{F}$ \\
\hline P8 & Clinical genetics & Researcher & M \\
\hline P9 & Reproductive medicine & Gynecologist & M \\
\hline P10 & Pediatrics & Pediatric neurologist & M \\
\hline P11 & Reproductive medicine & Gynecologist & $M$ \\
\hline P12 & Pediatrics & Pediatric neurologist & M \\
\hline P13 & Pediatrics & Researcher & M \\
\hline P14 & Clinical genetics & Researcher & $\mathrm{F}$ \\
\hline P15 & Clinical genetics & Researcher & $\mathrm{F}$ \\
\hline P16 & Clinical genetics & Counselor & $\mathrm{F}$ \\
\hline P17 & Clinical genetics & Clinical geneticist & $\mathrm{F}$ \\
\hline P18 & Neurology & Neurologist & $\mathrm{F}$ \\
\hline P19 & Clinical genetics & Researcher & $\mathrm{F}$ \\
\hline P20 & Pediatrics & Pediatric neurologist & $\mathrm{F}$ \\
\hline
\end{tabular}

mitochondrial genetics (the MITOCIRCLE-project). Moreover, a broad range of moral and cultural background perspectives were found between and within these countries. The respondents were spread over seven (academic) centers. All these centers offer PND for mtDNA disorders, mostly DNA-based tests. Three out of seven centers offer PGD (in general); these three centers would also offer, or already have offered PGD for mtDNA disorders. One center does not offer PGD, because it is legally not allowed.

The data were collected between August 2006 and April 2007. All interviews were conducted by $\mathrm{AB}$, except the interviews in Italy. Initial interview topics with open core questions were formulated after examination of the relevant literature. Consistent with standard qualitative research techniques, the interview topics evolved as the interviews progressed through an iterative process to ensure that the questions captured all relevant emerging themes (14). The interviews contained general topics and no close-ended questions (i.e. yes-or-no questions). The interviews lasted between 45 and 75 minutes. All interviews took place on the workplace of the respondent.

All the interviews were audiotaped and transcribed verbatim. Data analysis was based on the constant comparative method $(15,16)$. This entails the following steps. AB independently coded the full transcripts by identifying and labeling discrete units of texts that referred to one or more concepts relevant to the study purpose. Two researchers checked the codes for consistency (AK, GdW).
Through comparison across transcripts, the open codes were developed into higher order themes to provide a framework for coding subsequent transcripts. When no new thematic content was found in the interviews, subject enrolment was stopped. This process, called thematic saturation, is a welldescribed qualitative method to avoid unnecessarily large and repetitive data sets $(17,18)$. Finally, representative quotations were chosen to demonstrate the themes identified; these are noted in italics in the results section by participant number.

\section{Results}

We identified four main themes emerging from the interviews. Firstly, we illustrate the discussion among professionals as to what extent mitochondrial genetics differs from other areas in genetics, both technically and ethically. Secondly, we show the discomfort and doubts of professionals when an mtDNA mutation seems involved, because of the uncertainty that often remains after testing. Thirdly, we discuss how professionals struggle with the tension between, on the one hand, the ideal of reproductive autonomy and, on the other hand, the reality of their professional responsibility and complex clinical decision-making. Fourthly, we delineate the strategies used by professionals in order to make attempts to control the uncertainty.

Theme 1: Is mitochondrial genetics different?

My first question is, really, from first principles, is the issue of mitochondrial 


\section{Reproductive decision-making in mitochondrial DNA disorders}

disease ethically different to other diseases? (P1)

This question is evoked by most of the professionals. Most of them struggle with the question to what extent mitochondrial genetics resembles other areas in genetics. In other words, how peculiar is mitochondrial genetics? For some, the complexity is not exclusive for (reproductive) genetic testing in mitochondrial genetics, as no genetic test is without risks and uncertainties. From this perspective, uncertainty is an inherent part of genetic medicine and mitochondrial genetics should not be given a status aparte.

I would compare mtDNA with all the testing activities in the field of susceptibility testing, where, at the end, the contribution of the test results explains only $20 \%$ or $30 \%$ or $50 \%$ of the likelihood that the disease will develop or not. (...) We should not make it an exceptional case, although the uncertainty regarding the interpretation of test results is indeed somehow different (P17)

Most professionals, however, notify that the challenges of reproductive genetic testing and counseling are intensified in the context of mtDNA disease. Professionals frequently brought up the complexity of interpreting mtDNA heteroplasmy and the difficulty of excluding that an mtDNA mutation is involved.

Actually, the whole of genetic medicine is a continuum, you know, the blurriness of mitochondrial diseases is not, in principle, any different from the blurriness in Huntington's disease actually, because there are late onset mild forms, which just involve one little twitchiness, and there are young onset severe forms which involve dementia before your twenties. And actually, the genetic test doesn't separate those two, you can't separate them. (...) But in Huntington's, at least you have got one situation which is cast in tables and stone, that is, if you haven't inherited the change, you won't be affected. You can't say that with mitochondrial disease (P1)

The peculiarity is that you are never completely confident that an mtDNA mutation has been excluded. And the other compound of uncertainty is of course the level of heteroplasmy (...) So when you are dealing with heteroplasmy, the ethical problem is again that it is a quantitative genetics, it's not Mendelian 'yes or no' (P12)

Theme 2: Professional reactions when an mtDNA mutation is suspected

The uncertainty inherently linked to mitochondrial genetics is discomforting for the professionals involved, because they prefer to communicate certainties.

Also the physicians are very anxious when mtDNA mutations are involved. In those cases there are heated discussions in the staff. Physicians want certainty, which is exactly the problem (P16)

As a physician I would like to pass judgments as hard as a rock. Not ambiguous judgments. They [the couple] take a decision that is based on my opinion, which is not robustly enough. I find that regrettable $(P 7)$

Professionals indicate that these are difficult situations, not only for the couple but for the professional as well.

Until you make sure that no mtDNA mutation is involved, until that time you cannot say a word. So this is the most risky situation for the geneticist. To advise families. You can be face to face with a lady who is carrier, and you don't know. She has no symptoms, nothing (P12)

Some perceive the situation to be so uncertain that they are inclined to not offering specific type of tests anymore:

Our approach [with offering PND for mtDNA disorders] is so cautious that we have almost no experience (P20)

So, more and more often we do not propose enzyme-based testing for these mutations anymore. It's less and less, because we are not very confident of the results $(P 14)$

Others propose to not offering testing for specific types of mutations. Regarding some mutations, professionals are more insecure than with 
other mutations. When for example discussing PND and PGD for the m.3243A>G MELAS (mitochondrial myopathy, encephalopathy and stroke-like episodes) mutation professionals are more reserved than with other mutations:

\section{I think it is on the edge [PND and $P G D$ for MELAS] and it is questionable whether we should pass that line. It would keep me awake (P8)}

Many professionals thus show cautiousness when an mtDNA mutation is involved. As a consequence, some professionals exclude particular types of testing, or they exclude certain mtDNA mutations. What, then, once they have decided to go ahead with a specific couple? How do they view the counseling process?

Theme 3: Tension between the ideal of reproductive autonomy and the reality of clinical practice

For most professionals, reproductive decisionmaking is 'teamwork', in which the clinician, the researchers and the couple together form a team. However, to be able to make informed decisions, the couple should be provided with information on at least a part of the complexities and uncertainties of mitochondrial genetics. They should also, according to professionals, understand the remaining uncertainties. Although all professionals identify reproductive autonomy as a core value, they do not agree to whether couples are capable of making autonomous decisions when the information provided is so complex and ambiguous. Some are quite positive about the possibilities to explain the ins and outs:

I use images, symbols and examples and they understand it very well. Believe me, even the very simple, not-educated are not stupid (P12)

For me, there is absolute no problem in using tests for which we have difficulties or which have limits, as far as you inform patients on these limits if you have doubts. So this is a general approach in medicine: we have a possible treatment for you, we don't know yet if it will work or not, nor whether it may have adverse effects. But if you inform the patient, in the end the patient, after balancing, can make her own decision (...) It's [informing couples] a matter really of time. I know that for complicated decisions you need at least 45 minutes or one hour with a couple or a patient. And most physicians cannot spend that much time with patients. But if you have the resources to do that, it works (P17)

Others, however, question whether the nuances of mitochondrial genetics can be explained to couples:

One of the difficulties, of the ethical bits that actually no one challenges is the fact that actually to understand this [information regarding mtDNA], you have got to have a certain level of intellectual capacity. And this is an awful thing to say, but the truth is that only a proportion of the population can handle this information and understand it, I believe. (...) If a physician cannot make a decision, based on the evidence, how in earth the others? (P1)

The clinical phenotype varies and people visit us to have a healthy child, so you really have to counsel them well in order to explain everything. The hospital setting implies that people are inclined to think that everything will be all right and that their child will be healthy after all (P8)

\section{Theme 4: Strategies to control the uncertainties}

Because of the uncertainties in predicting the phenotype and the complexities in explaining these uncertainties, some professionals do not offer specific types of genetic testing or they exclude testing for some mutations. Others, however, are more positive toward offering tests, but this is accompanied with the introduction of several mechanisms to control and reduce the uncertainties. Most professionals are looking for 'steady ground', for control.

Several strategies are used to try to control the uncertainty. First of all, many professionals introduce some kind of quality requirement: they emphasize that only very experienced and wellequipped professionals should offer testing in the context of mtDNA disease. Furthermore, they also stress that the centers that currently offer genetic testing for mtDNA disease are highly qualified and conduct cutting-edge research.

Doing the biochemistry is really tricky. So you don't want people doing it who don't have a lot of experience (P3) 


\section{Reproductive decision-making in mitochondrial DNA disorders}

Also the patient organizations regard the European centers at cutting edge in mitochondrial genetics (P12)

Secondly, many professionals emphasize the importance of international cooperation in order to improve scientific knowledge.

We have got to work together as a [mitochondrial] community on this, because each individual centre still has a very limited amount of information (P3)

In order to generate more knowledge with regard to mtDNA we should establish big databases, as well as multidisciplinary and international research, like the MITOCIRCLE project. The most important is that we share and exchange our experience (P8)

What I think is useful is that we have different approaches in different groups, to have different answers. Not all the labs can do everything so it is good to specialize and we will see after two or three years of research what is the best way to go (P14)

A third reaction to gain control contains the efforts of professionals to try to calculate the recurrence risks as precisely as possible. Professionals seem to feel uncomfortable that they cannot fulfill what they regard as their main job, namely providing expert knowledge on the basis of data that are precise and well understood, also in terms of clinical consequences. They are very anxious to find out the precise risks and to communicate these to their patients.

What interests me the most really is just how difficult it is to explain recurrence risks to patients. It is easy mathematically, but really what does that mean for a person, you know, when you are faced with a decision whether or not you should go ahead with a pregnancy. Now that's just separate to include a 25,50 or $75 \%$ risk in rare circumstances. What's happening when you start breaking that up all in between? What on earth does that mean? $18 \%$ or $33 \%$, what does that mean? (...) Sometimes, as a kind of opposite argument to what I just presented to you about the uncertainty of the data, I sometimes think maybe we are trying to be too good, too accurate (P1)

\section{Discussion}

Our results show that all professionals feel that the inherent challenges of reproductive genetic testing and counseling are intensified in the context of mtDNA disease (theme 1). Even for the few professionals that did not explicitly state that they perceive mitochondrial genetics to be different, one may still infer this from their reactions to offering PND or PGD (theme 2). The uncertainties linked to mitochondrial genetics seem to confuse professionals. They tend to regard these uncertainties as conflicting with their task of providing accurate information when counseling couples. Many feel uncomfortable by not being able to communicate definite and unambiguous information. Mitochondrial genetics is currently characterized by two types of uncertainty: uncertainty in predicting the recurrence risk of a couple and uncertainty in predicting whether a child will develop clinical disease symptoms, and if so, how serious these will be. So, when an mtDNA mutation is involved, it is not business as usual.

This has consequences for the framework in which professionals usually assist and counsel their patients. Genetic counseling is usually perceived as a process aimed at enabling couples to take meaningful decisions. Information is not given as an end in itself, but as a means of helping people to reach a personally satisfactory decision (19). Similarly, most professionals in our study view reproductive decision-making as both a process and as 'teamwork', in which the clinician, the researchers and the couple together form a team. However, in order to be able to make informed decisions, the couple should be informed about at least a part of the complexities and uncertainties of mitochondrial genetics. All professionals identify reproductive autonomy as a core value, but they disagree as to whether couples facing the risk of transmitting an mtDNA mutation are capable to make informed, autonomous decisions with regard to the reproductive options open to them (theme 3). Mitochondrial genetics may therefore be perceived as a test case for reproductive autonomy. To answer the ethical question whether and under which conditions PND or PGD in the context of mtDNA disease is acceptable falls outside the scope of this paper, but is discussed elsewhere $(3,6)$. It is at the least interesting that in our interviews different professionals draw different conclusions. Whereas a part of the professionals hold the opinion that reproductive autonomy is not endangered, others doubt whether the nuances of mitochondrial genetics can still be explained. 
Because of the uncertainties in predicting the phenotype and the difficulties in explaining the ins and outs, some professionals conclude that either specific reproductive genetic tests should currently not be offered or that these tests should not be applied to all mtDNA mutations. Others draw the conclusion that one may go ahead, but only in accompaniment of several mechanisms to control and reduce the uncertainties (theme 4). So, these tests may be offered, but only by professionals and laboratories with the highest qualifications and only in the context of the best possible international collaboration and research programs. Furthermore, these professionals try calculating and explaining the recurrence risks as adequately as possible. They hold the view that the best possible way of dealing with uncertainties is to calculate the risks as precisely as possible.

Although knowing the magnitude of any remaining risks is necessary for determining whether testing can justifiably be offered, and although it is interesting from a scientific point of view, more precise calculations will not always provide the couples involved with a better basis for decisionmaking. Even apart from the fact that-as studies indicate-patients have a poor understanding of quantitative risk information (20), it could be questioned whether it will be helpful for couples to know whether the risk that their child will be clinically affected is $33 \%$ or $39 \%$ (with the qualification that even mtDNA specialists are currently unable to predict such a risk level). From this perspective, the last quoted citation is striking: perhaps professionals are trying to be too accurate. Indeed, research suggests that counselees are not very interested in more precise risk information. They long for information providing them with a high degree of certainty about expected outcomes $(21,22)$. Whereas genetic information is normally already replete with uncertainties, this is even more so in the context of mitochondrial disease.

Although we can imagine that some professionals conclude that reproductive genetic testing for couples affected by an mtDNA mutation is too challenging, we think that this should be decided on a case-by-case basis. After all, some reproductive options may considerably bring down the transmission risk. Although challenging, this still can be a meaningful option for couples who are willing and able to deal with the uncertainties involved. In our view, it belongs to the responsibility of professionals working in this field to try to help affected couples to make a well-informed decision, even if this cannot always consist in providing them with precise data about remaining risks. The uncertainties inherently linked to genetic information in general and to mitochondrial genetics specifically could be the starting point of the counseling process. Furthermore, studies show that counselees find information about the consequences of having an affected child and of alternative reproductive options very helpful $(19,22)$. So, professionals could pay attention to the consequences of living with a child with a mtDNA disorder, the range of possible clinical manifestations, the expected quality of life and the possibilities and limitations for the child (and its siblings). As predicting whether a child will be clinically affected (and if so, how serious) may remain difficult, it could be helpful to discuss several scenarios with the couple (i.e. the worse case scenario as well as a more favorable outcome) (23). Here, the role of the counselor is to help people to see what all the possible consequences of the different reproductive options are and how these relate to their circumstances and values (24). This implies that the counselor and couple should discuss the uncertainties and moral dilemmas involved, the different reproductive strategies for carriers of mtDNA mutations and their pros and cons.

Obviously, this type of counseling is timeconsuming. We recommend to seriously building in extra time to provide people with the appropriate information. This is a sine qua non for guaranteeing that reproductive autonomy is more than just a catchy term and for assuring that people make well-informed decisions. Furthermore, to concentrate testing and counseling for mtDNA disease in some specialized centers guarantees that researchers and counselors are capable of developing more experience in mtDNA based counseling.

\section{Conclusion}

This paper illustrates the impact of reproductive counseling and decision-making in the context of mtDNA disease on professionals. Mitochondrial genetics is currently characterized by two types of uncertainty: uncertainty in predicting the recurrence risk of a couple and uncertainty in predicting whether a child will develop clinical disease symptoms, and if so, how serious. This study shows that professionals feel discomfort when handling, interpreting, and explaining uncertain or ambiguous data. As some professionals doubt whether the nuances of mitochondrial genetics can still be explained, mitochondrial genetics may be perceived as a test case for reproductive autonomy. 


\section{Reproductive decision-making in mitochondrial DNA disorders}

Furthermore, this study may be perceived as an example of how professionals deal with the inherent limitations in genetic knowledge representing the state of the art. After all, novel developments in medical genetics will continuously confront professionals with ambiguous information. Part of the uncertainty in mitochondrial genetics may be caused by insufficient knowledge and may therefore be reduced by future research. However, part of the uncertainty may be inherently linked to mtDNA genetics. In that case, reproductive counseling and decision-making will always remain complex in the context of mtDNA disease.

\section{Acknowledgements}

We would like to thank all respondents for their time and for sharing their experiences. We particularly thank Dr Valeria Tiranti, for conducting the interviews in Italy.

This work was supported by a grant from the European Union 6th Research Framework Program (the MITOCIRCLE project contract no. 005260) and by GROW - School for Oncology and Developmental Biology, Maastricht University.

\section{References}

1. Mol A. Meer technologie: meer praten. Med Contact 1995: 51/52: 1652-1654 [in Dutch].

2. Bredenoord AL, Pennings G, Smeets HJ et al. Dealing with uncertainties: ethics of prenatal diagnosis and preimplantation genetic diagnosis to prevent mitochondrial disorders. Hum Reprod Update 2008a: 14: 83-94.

3. Bredenoord AL, Dondorp W, Pennings G et al. Preimplantation genetic diagnosis for mitochondrial DNA disorders. Ethical guidance for clinical practice. Eur J Hum Genet. Epub 27 May 2009. DOI: 10.1038/ejhg.2009.88.

4. Bickerstaff H, Flinter F, Yeong CT, Braude P. Clinical application of preimplantation genetic diagnosis. Hum Fertil 2001: 4: $24-30$.

5. Steffann J, Frydman N, Gigarel N et al. Analysis of mtDNA variant segregation during early embryonic development: a tool for successful NARP preimplantation diagnosis. J Med Genet 2006: 43 (3): 244-247.

6. Bredenoord AL, Dondorp WJ, Pennings G et al. PGD to reduce reproductive risk: the case of mitochondrial DNA disorders. Hum Reprod 2008b: 23 (11): 2392-2401.
7. Brown DT, Herbert M, Lamb VK et al. Transmission of mitochondrial DNA disorders: possibilities for the future. Lancet 2006: 368 (9529): 87-89.

8. Chinnery PF, Majamaa K, Turnbull D et al. Treatment for mitochondrial disorders. Cochrane Database of Syst Rev 2006: Issue 1. Art. No.: CD004426. DOI: 10.1002/14651858. CD004426.pub2.

9. Munnich A, Rotig A, Chretien D et al. Clinical presentation of mitochondrial disorders in childhood. J Inherit Metab Dis 1996: 19: 521-527.

10. Taylor RW, Turnbull DM. Mitochondrial DNA mutations in human disease. Nat Rev Genet 2005: 6 (5): 389-402.

11. Thorburn DR, Dahl HHM. Mitochondrial disorders: genetics, counseling, prenatal diagnosis and reproductive options. Am J Med Genet Semin C Med Genet 2001: 106: 101-114.

12. Patton M. Qualitative research and evaluation methods. Thousand Oaks, CA: Sage Publications, 2002

13. Polit DF, Beck CT. Nursing research: principles and methods, 7th edn: Lippincott Williams \& Wilkins: Philadelphia 2003.

14. Britten N. Qualitative interviews in medical research. BMJ 1995: 311: 251-253.

15. Strauss AL, Corbin J. Basics of qualitative research: techniques and procedures for developing grounded theory. London: Sage Publications, 1998.

16. Malterud K. Qualitative research: standards, challenges, and guidelines. Lancet 2001: 358: 483-488.

17. Guest G, Brunce A, Johnson L. How many interviews are enough? An experiment with data saturation and variability. Field Methods 2006: 18: 59-82.

18. Denzin NK, Lincoln YS, eds. The Sage handbook of qualitative research, 3rd edn. Thousand Oaks, CA: Sage Publications, 2005.

19. Shiloh S, Gerad L, Goldman B. The facilitating role of information provided in genetic counseling for counselees' decisions. Genet Med 2006a: 8 (2): 116-124.

20. Lloyd AJ. The extent of patient's understanding of the risk of treatments. Qual Health Care 2001: 10(Suppl. 1): i14-i18.

21. Zuuren van F, Schie van EC, Baaren van NK. Uncertainty in the information provided during genetic counselling. Patient Educ Couns 1997: 32 (1-2): 129-139.

22. Shiloh S, Gerad L, Goldman B. Patients' information needs and decision-making processes: what can be learned from genetic counselees? Health Psychol 2006b: 25 (2): 211-219.

23. Abramsky L. Counselling around prenatal testing. In: Abramksy L, Chapple J, eds. Prenatal diagnosis. The human side, 2nd edn. Cheltenham: Nelson Thornes Ltd, 2003: 70-82.

24. Marteau TM, Dormandy E. Facilitating informed choice in prenatal testing: how well are we doing? Am J Med Genet 2001: 106 (3): 185-190. 